\title{
THE "SAWTOOTHED" ORB WEB OF EUSTALA SP. (ARANEAE, ARANEIDAE) WITH A DISCUSSION OF ONTOGENETIC CHANGES IN SPIDERS' WEB-BUILDING BEHAVIOR*
}

\author{
BY \\ William G. Eberhard \\ Smithsonian Tropical Research Institute \\ and \\ Escuela de Biología, Universidad de Costa Rica \\ Ciudad Universitaria, Costa Rica
}

Convergence has been common in the evolution of orb-weaving spiders' webs, and structures such as stabilimenta, reduced orbs, spring lines, meshes at the side of the orb, and asymmetrically extended "ladder webs" have arisen independently in a number of different groups. This paper describes brief observations of Eustala sp. that demonstrate still another apparent convergence that is perhaps more surprising than some of the others since the adaptive advantage of the convergent design is at first glance unclear.

Ontogenetic changes in web design are also documented for $E \mathbf{E}$ stala sp.; younger individuals make more generalized or less derived webs than those of adults. Data on ontogenetic changes in the web forms of other spider species are summarized, and it is shown that this is a common ontogenetic pattern in spiders. The possible significance of this evolutionary pattern is discussed.

Observations were made in February 1984 in Parque Nacional Corcovado on the Osa Peninsula of Costa Rica in second growth along a small stream near the Sirena station. Webs of six large nymphs and adult females and of two very young nymphs were observed. The construction of three of these webs was observed between 7 and 11 PM.

Spiders were kındly identified by $\mathrm{H}$. W. Levi. They apparently represent an undescribed species; voucher specimens (\#2345, SA1-127b, and SAE-106) have been deposited in the Museum of Comparative Zoology in Cambridge, Mass. 02138, U.S.A.

*Manuscript received by the editor November 16, 1984 


\section{Webs of LARger NyMPhS AND AdUlTS}

The webs of larger individuals of Eustala sp. (Figures 1 and 2) had several features that were recognizably orb-like. Radial non-sticky lines converged on a single point and were attached to a small, more or less circular hub where the spider rested. Some of the radial lines were fastened directly to a leaf, but other longer ones were attached

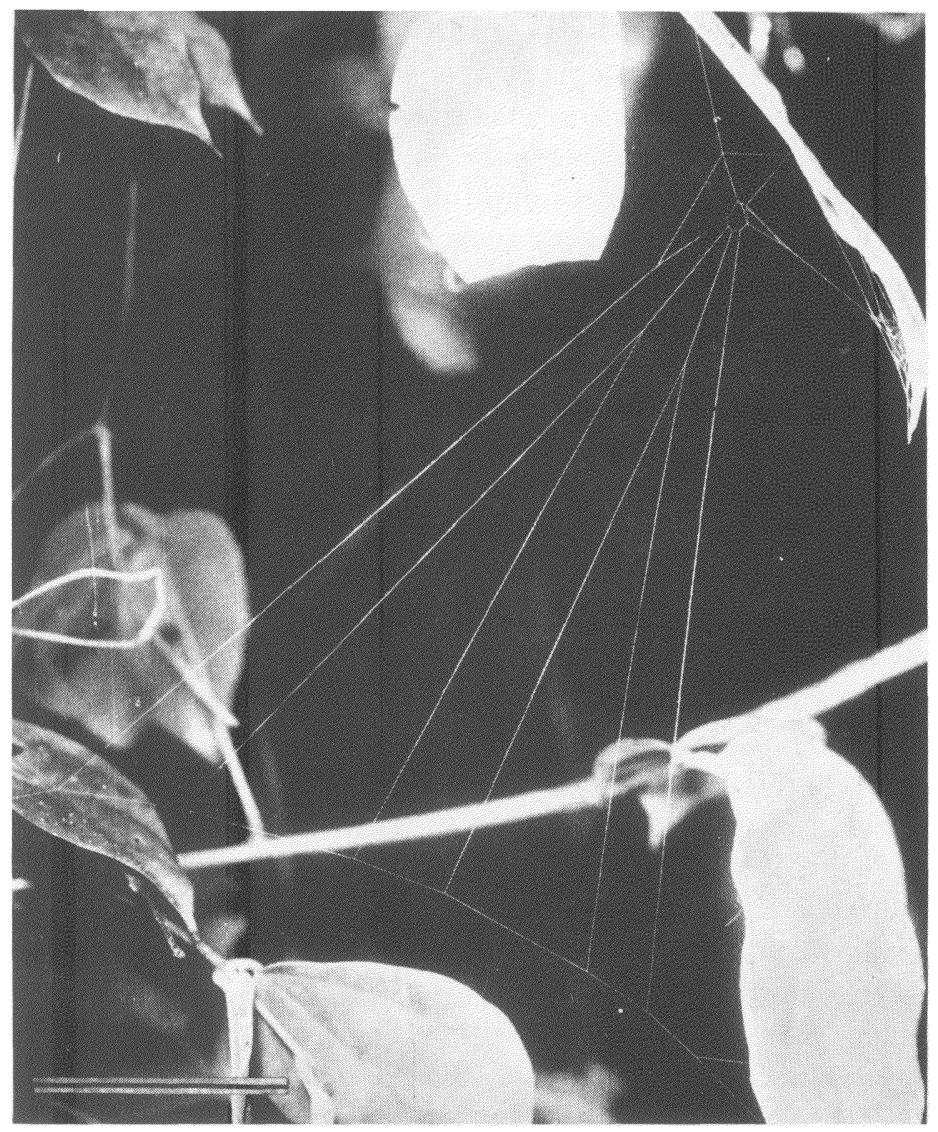

Fig. 1. Web of an adult female Eustala sp. The spider rested under the hub-like structure at the upper right. The retreat is visible under the leaf at the far right. Scale marker $=5 \mathrm{~cm}$. 
to a supporting frame line or lines attached at either end to a leaf. The numbers of radial lines varied between 5 and 8 .

The least orb-like aspect of the webs was the placement of the sticky lines. Instead of forming a more or less spiral pattern centered on the hub, the sticky lines ran both radially and along the frame lines in a sawtooth pattern. As shown in Fig. 2, some of the sticky lines ran directly along non-sticky radial lines, while others spanned spaces between radial and frame lines.

\section{COnstruction Behavior}

Construction behavior did not vary among the individuals observed, and confirmed the impression that the webs are modified orbs. After an extended period of exploration and repeated replacement of the few lines already laid, the spider finally began by constructing radial and frame lines. One frame construction observed carefully was essentially identical to the frame construction behavior of other araneids that have been observed (e.g. Coddington in press and references therein, pers. obs. of Leucauge sp. nr. venusta). Subsequent radial lines were attached to the frames with the same behavior as that of other araneine species (Eberhard 1982). No hub loops were laid until the radii were complete, when the spider turned $360-720^{\circ}$ at the hub laying a more or less circular non-sticky line, then abruptly switched to laying a non-sticky line apparently equivalent to the temporary spiral of typical orb weavers. This line was laid at some distance from the hub, and the spider did not return all the way to the hub after each attachment; instead it reached laterally to contact each new radius. The temporary spiral was only attached to the longer radii, and consisted of a single incomplete "loop" (Fig. 2).

The spider paused perhaps $15-30$ seconds before commencing the sticky line. In one case it clearly moved out to the frame along the radius on which it had ended the tsp before commencing sticky line production; this detail was not checked in the others. It then moved inward along the radius, pulling with quick alternate movements of its legs IV on a sticky line that emerged as it moved. In one case I could see that the spider attached this sticky line at least twice to the radius along which it was moving. When the spider reached the temporary spiral line, it paused and pulled sticky line with several more strokes of its legs IV, and then attached it to the radius. 


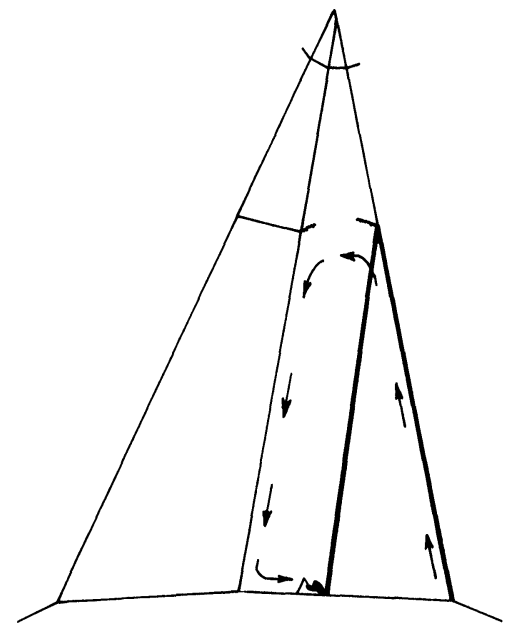

a

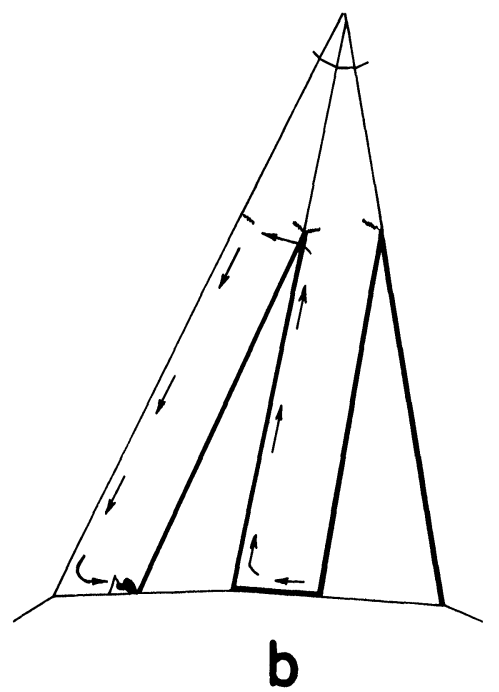

Fig. 2. Building behavior of an adult Eustala sp. (thicker lines are sticky thread). a) As the spider laid sticky line, it moved inward (upward in the diagram) along a radial line until it reached the temporary spiral where it attached the sticky line. Then it moved across the temporary spiral to the next radius, and then outward to the frame. Here it moved back partway toward the original radius, and attached the sticky line again. b) the spider then retraced its steps along the frame and went inward along the next radius, repeating the cycle of behavior shown in a.

Without making further attachments, it moved on along the temporary spiral to the next radius and outward along this radius until it reached the frame. I was not able to observe temporary spiral destruction directly, but since temporary spirals were absent in completed webs and this was the only time during web building when spiders passed near this area, I assume that the spiders removed the spiral lines as they moved across them as do other araneids. On reaching the frame the spider performed a behavior never to my knowledge observed in any orb weaving araneid: it moved contrary to the circular direction in which it had been moving (i.e. if it had moved clockwise along the temporary spiral, it moved counterclockwise along the frame - Fig. 2.) before attaching the sticky line; then it reversed direction once again until it encount- 
ered the next radius (the one along which it had just moved to the frame), and the cycle just described was then repeated (Fig. 2). When moving outward along radii that were attached directly to the substrate instead of to a frame line, the spider omitted the "backward" segment of the behavior, and simply returned inward along the radius, producing a spiked rather than sawtooth pattern of sticky line.

Sticky line construction terminated when the spider encountered a sticky line it had already laid, and the sticky lines were thus laid in a single 360 degree trip around the web. The spider then moved to the hub of the web and finished web construction by removing the small mesh of lines inside the hub loops, just as do many other araneids (Eberhard 1982).

\section{WEBS OF VERY SMALL NYMPHS}

Two nymphs were found on complete, typical orb webs, one in the center of such a web (Fig. 3), and the other crouching in a typical retreat (see below) that was connected to a nearby orb of similar design. Construction behavior of these spiders was not observed. Immature spiders are generally difficult to identify, but these nymphs had the same unusual combination of characteristic white abdomens, white cephalothoracic markings, and dark pink prolateral surfaces on their legs and were of the same size and shape as others that emerged in captivity from egg sacs found with adult females. The nymphs with webs occured on the same Heliconia leaves where I found four other individuals (two mature females) of Eustala sp., and they had the same unusual retreat design as the older spiders (below). Thus the nymphs' identity is fairly certain despite their lack of diagnostic genitalic characters (voucher specimens are deposited in the Museum of Comparative Zoology in Cambridge, Mass.).

\section{RETREATS}

The retreats, which are apparently unique among araneids in their design, were on the undersides of leaves (Fig. 1). The spider sat in the bottom of an inverted truncated cone-like structure, pressing its body flat against the leaf. The flared sides of the cone, which were supported by a small, inconspicuous meshwork of threads had 


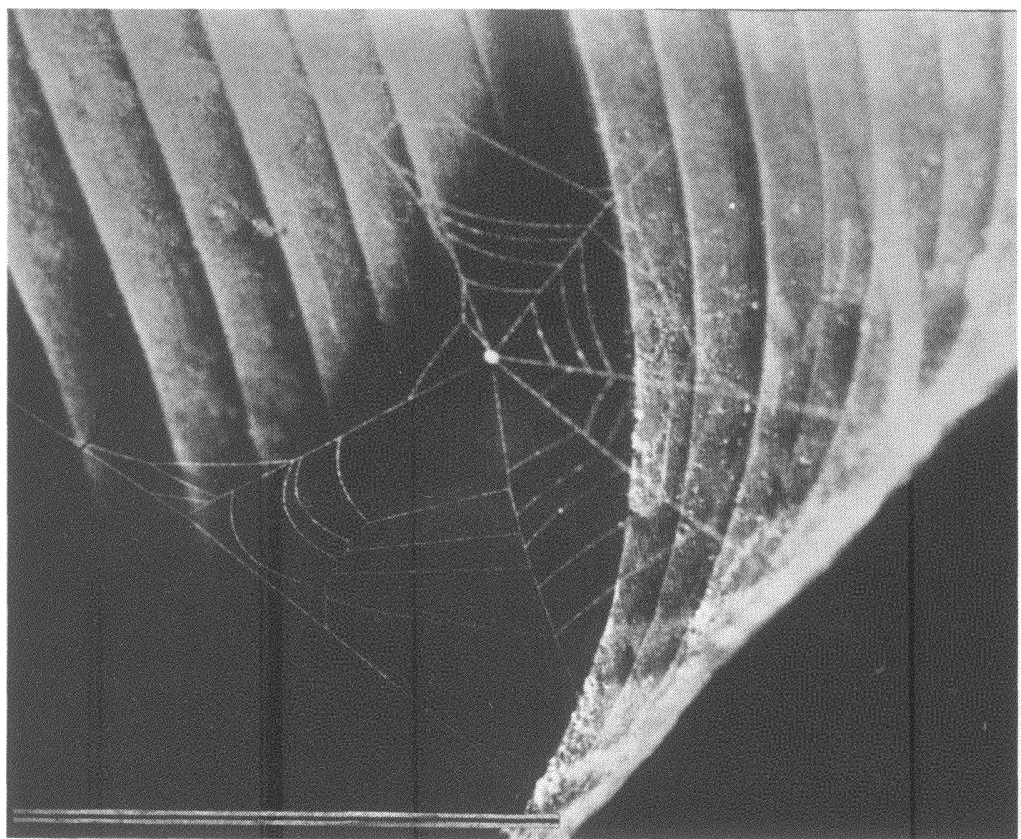

Fig. 3. Web of a young Eustala sp. The spider is resting at the hub. Scale line $=5$ cm.

numerous flecks of white silk, and the radial arrangement of the retreat plus the flecks gave the strong impression that the spider was dead and had been attacked by a fungus that was producing fruiting bodies.

\section{Discussion}

The webs of adult Eustala sp. differ dramatically from the more or less typical orbs of other Eustala species (Eberhard 1975, 1976, unpub. obs. of at least 10 other species). Although the usefulness of orb web geometry in grouping species in genera has yet to be demonstrated, the differences documented here are probably unusual.

There is a striking similarity between the webs and building behavior of larger Eustala sp. and those of the very distantly related uloborid Polenecia (=Sybota) producta (Weihle 1931) (Fig. 4): 


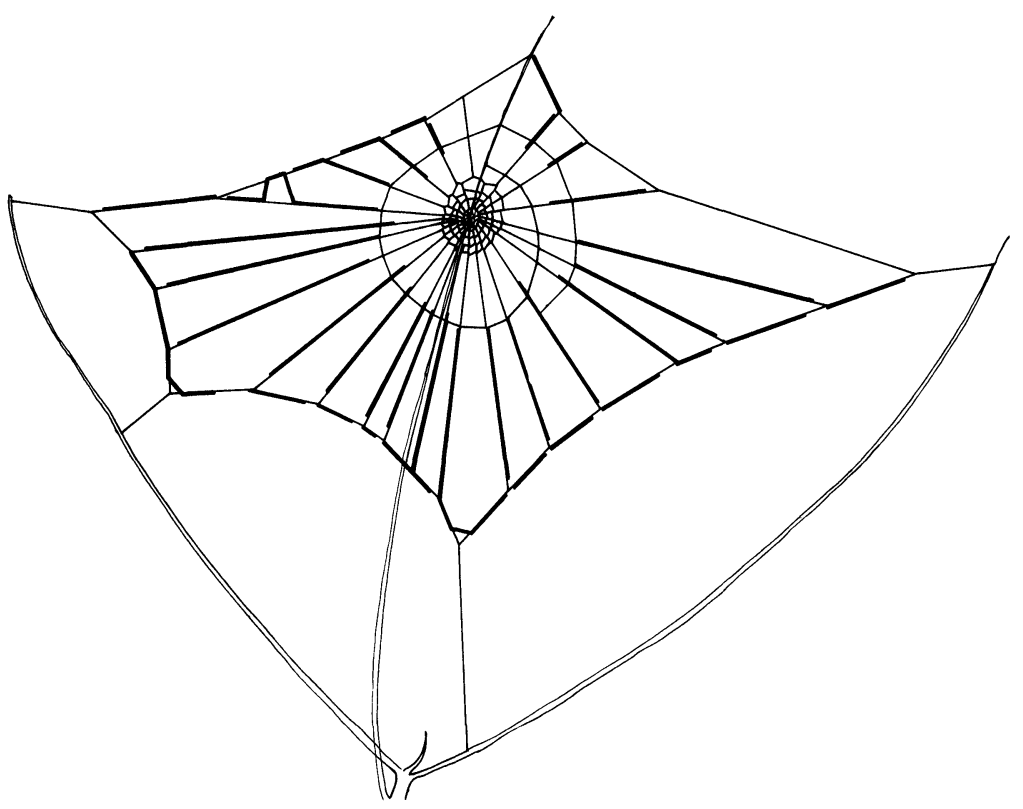

Fig. 4. Web of Polenecia (=S!'bota) producta (after Wiehle 1931). Thicker lines are sticky thread.

sticky lines run along both radii and frame threads; the sticky lines on the radii are laid starting from the periphery and working inward; and the sticky lines on the radii extend to about where the temporary spiral crosses the radii. Wiehle's description of building behavior suggests that just as in Eustala sp., Polenecia lays sticky silk on each radius in succession, and thus probably makes only one $360^{\circ}$ circuit of sticky silk construction before finishing. Major differences between Polenecia and Eustala sp. webs include Polenecia's lack of temporary spiral destruction (also occurs at least sometimes in the related uloborid Hyptiotes - Opell 1982 - Fig. 1; pers. obs.), periodic interruption of sticky line production (also occurs in Hyptiotes Wiehle 1927, Marples and Marples 1937), and a general lack of sticky lines spanning spaces between radii and frames. Polenecia is probably derived from an orb-spinning uloborid ancestor (Opell 1979). Other Eustala species and species in related genera spin orbs 
(above), so the sawtoothed web is probably also derived from a typical orb. Thus the two genera have almost incredibly converged on the same strange web architecture, and employ many of the same behavioral sequences to produce it.

A possible explanation for this convergence is related to the fact that sticky lines are usually only able to absorb about one tenth as much momentum as radial lines in completed orbs (Eberhard in press). By laying their sticky lines on radial and frame lines, Eustala sp. and Polenecia effectively increase the sticky lines' ability to stop moving prey. Such relatively strong sticky lines will most effectively intercept prey when they are placed far enough apart that the probability of "wasting" more than one line intercepting any given prey is reduced (Chacon and Eberhard 1980). Thus the two webs may be adaptations to strengthen sticky lines and array them so as to increase their probabilities of intercepting prey.

The interpretation that the web form of older individuals of $E \mathbf{E}$ stala sp. is derived from an orb-web is supported by the fact that very young individuals construct typical orbs. A review of the literature on ontogenetic changes in spiders' webs shows that similar tendencies for younger individuals to spin less derived webs occur in a number of other orb weaving araneids, including Zygiella (Petrusewiczowa 1938), Scoloderus (Eberhard 1975), Nephila (Robinson and Robinson 1973, pers. obs.), Herennia (Robinson and Lubin 1979a), Tetragnatha (=Eucta) (Crome 1954), and Pachygnatha (Bristowe 1958). Very young Uloborus conus (Uloboridae) sometimes also omit the presumably derived cone structure that is consistently present under the orbs of mature females (Y. D. Lubin, pers. comm.). Some species of non-orb weaving spiders also have less derived juvenile webs and/or behavior. These include the psechrid Fecenia (Robinson and Lubin 1979b), the mygalomorph Diplura (younger spiders more often make webs without lines above the sheet, and the funnel retreat is more often nearer the center of the sheet-A. Deccae, pers. comm.; ancestral spiders presumably lived in holes where silk accumulated on the surface of the ground more or less symmetrically around the edges of the hole), and (perhaps) web-weaving oxyopids of the genus Tapinillus (Griswold 1983, Mora in press). Still other possible examples are the salticid genera Euryattus and Simaetha, in which younger spiders routinely spin sheet webs for prey capture while older individuals only seldom 
spin webs (R. Jackson, pers. comm.). This case must be considered tentative, since the suspected ancestral nature of web spinning (e.g. Jackson and Blest 1982) in Salticidae is not yet firmly established.

The designs of the webs of other orb weavers (Araneus, Neoscona, Argiope, Leucauge) also change as the spiders mature (Mayer 1953, Witt and Baum 1960, Reed et al 1969, Risch 1977, Robinson and Robinson 1978, Maroto unpub.); although in these cases probable ancestral web forms have not been determined, younger individuals of Araneus, Neoscona and Argiope conform to expectations as they build more similar webs than do adults (Risch 1977) (in Argiope the sex of young spiderlings also affects the web design!Robinson and Robinson 1978).

There are ontogenetic changes in the webs of several other species of spiders, but they differ from the cases just cited. Very young Zygiella $x$-notata can build only incomplete orbs or tangles prior to the age at which they normally emerge from the egg sac (Peters 1969). These changes in behavior differ from the examples above in that they probably stem at least in part from incomplete development of silk glands and from the completion of embryonic cytodifferentiation processes (Peters 1969). Young Uloborus, Philoponella, Zosis, and other uloborids spin "orbs" in which sticky cribellar silk is replaced by mats of very fine radial and non-radial lines (Szlep 1961, Eberhard 1977), but again in this case the spiderlings also lack the morphological structures necessary to produce the types of silk used by older individuals.

There are also groups (e.g. Miagrammopes, Hyptiotes, Ogulnius) in which young spiders spin the same derived web form as the adults (Lubin et al. 1979, Opell 1982, pers. obs.). There is, however, apparently only one clear case of more derived webs being used by younger spiders: this is Mastophora dizzydeani, a species whose ancestors made orbs but in which young spiders generally spin no trapping web whatsoever and adults usually make a remnant web in the form of a sticky globule. There is, however, a probable selective advantage in greater web reduction in smaller individuals, since surface to volume relations may make the use of globules especially difficult for smaller spiders (see Eberhard 1980).

Spiders thus show the same trend in their behavior that is well known in the morphology of many animal groups: adult characters tend to be more derived than those of the young. Why this should 
occur in web building behavior is not clear. Simple adaptive explanations of the changes in spiders' behavior seem unlikely in at least some cases: for example an open sector allowing easier access to the web from a hidden retreat would seem advantageous for young as well as older individuals of Zygiella; and the displacement of the hub toward the top of Nephila webs would presumably result in more rapid attacks by young as well as older spiders (Masters and Moffat 1983). Some arguments attempt to explain the relative conservatism of younger individuals' morphology as a result of the young being shielded from the action of natural selection from the surrounding environment (e.g. Darwin 1859), and are clearly not applicable to the webs. Others cite the effects of canalization in development and the likelihood that modifications expressed earlier in ontogeny will have especially low adaptive values because their consequences are magnified by subsequent growth (see Futuyma 1979 , Gould 1977). This is probably true for some morphological traits, but innate behavioral characters do not obviously build upon each other, and the argument thus loses credibility. Young spiderlings are able to spin complete orbs the first time they try, and in at least some cases (e.g. Eustala sp., Fecenia, Scoloderus) the spiderlings' webs are made of (presumably) similar types of silk used in approximately the same relative quantities as the silk in adult webs. Learning probably plays little part in the ontogenetic changes in orb-weavers' behavior (Petrusewiczowa 1938, Mayer 1953, Reed et al. 1970, Robinson and Robinson 1976). Thus the reason for greater conservatism in juvenile web design remains a mystery.

\section{ACKNOWLEDGEMENTS}

The observations were made while I participated in an $\mathbf{O}$. T. S. field course led by D. Futuyma and F. Putz. H. W. Levi kindly identified spiders, and he and M. J. West-Eberhard read a preliminary draft of the manuscript. Discussions with D. B. Wake helped focus questions regarding ontogeny, and Y. D. Lubin, A. Deccae and $\mathbf{R}$. Jackson generously allowed me to use unpublished observations. Financial support was provided by the Vicerrectoría de Investigacion of the Universidad de Costa Rica. 


\section{REFERENCES}

BRISTOWE, W. S.

1958. The world of spiders. Collins, London. 1-304.

Cuacon, P. and W. G. Eberhiard

1980. Factors affecting numbers and kinds of prey caught in artificial spider webs, with considerations of how orb webs trap prey. Bull. Brit. arachnol. Soc. 5: 29-38.

Comdington, J.

in press. The monophyletic origin of the orb web. in W. Shear (ed.) Spider webs and spider behavior. Stanford Univ. Press.

Crome, W.

1954. Beschreibung, Morphologie und Lebensweise der Eucta kaestneri sp. n. (Araneae, Tetragnathidae). Zool. Jb. (Syst.). 82: 425-452.

DarWIN, C.

1859. The origin of species by means of natural selection. John Murray, London.

Ekrirhard, W. G.

1975. The "inverted ladder" orb web of Scoloderus sp. and the intermediate orb of Eustala (?) sp. Araneae: Araneidae. J. nat. Hist. 9: 93-106.

1976. Photography of orb webs in the field. Bull. Br. arachnol. Soc. 3: 200-204.

1977. The webs of newly emerged Uloborus diversus and of a male Uloborus sp. (Araneae: Uloboridae). J. Arachnol. 4: 201-206.

1980. The natural history and behavior of the bolas spider Mastophora dizzydeani sp. n. (Araneidae). Psyche 87: 143-169.

in press. Effects of orb web geometry on prey interception and retention. in W. Shear (ed.) Spider webs and spider behavior. Stanford Univ. Press.

Futuyma, D.

1979. Evolutionary biology. Sinauer, Sunderland, Mass.

Goul.D, S. J.

1977. Ontogeny and phylogeny. Harvard Univ. Press, Cambridge, Mass.

Griswol.D, C. E.

1983. Tapinillus longipes (Taczanowski), a web-building lynx spider from the American tropics (Araneae: Oxyopidae). J. nat. Hist. 17: 979-985.

JACKSON, R. R. AND A. D. BLest.

1982. The biology of Portia fimbriata, a web-building jumping spider (Araneae, Salticidae) from Queensland: utilization of webs and predatory versatility. J. Zool., Lond. 196: 255-293.

LEGuelte, L.

1966. Structure de la toile de Z!'giella $x$-notata $\mathrm{Cl}$. (Araignees, Argiopidae) et facteurs que regissent la comportement de l'araignee pendant la construction de la toile. These Pub. Univ. Nancy. 1-77.

Lubin, Y. D., W. G. Eberhard, and G. G. Montgomery.

1978. Webs of Miagrammopes (Araneae: Uloboridae) in the Neotropics. Psyche 85: 1-23. 
SZLEP, R.

1961. Development changes in web-spinning instinct of Uloboridae: construction of the primary-type web. Behaviour 27: 60-70.

WiEHLE, $\mathrm{H}$.

1927. Beitrage zur Kenntnis des Radnetzbaues der Epeiriden, Tetragnathiden und Uloboriden. Z. Morph. Okol. Tiere. 9: 468-537.

1931. Neue Beitrage zur Kenntnis des Fanggewebes der Spinnen aus des Familien Argiopidae, Uloboridae und Theridiidae. Z. Morph. Okol. Tiere. 22: 348-400.

WitT, P.N. AND R. BAum.

1960. Changes in orb webs during growth (Araneus diadematus Clerck and Neoscona vertebrata McCook). Behav. 16: 309-318. 

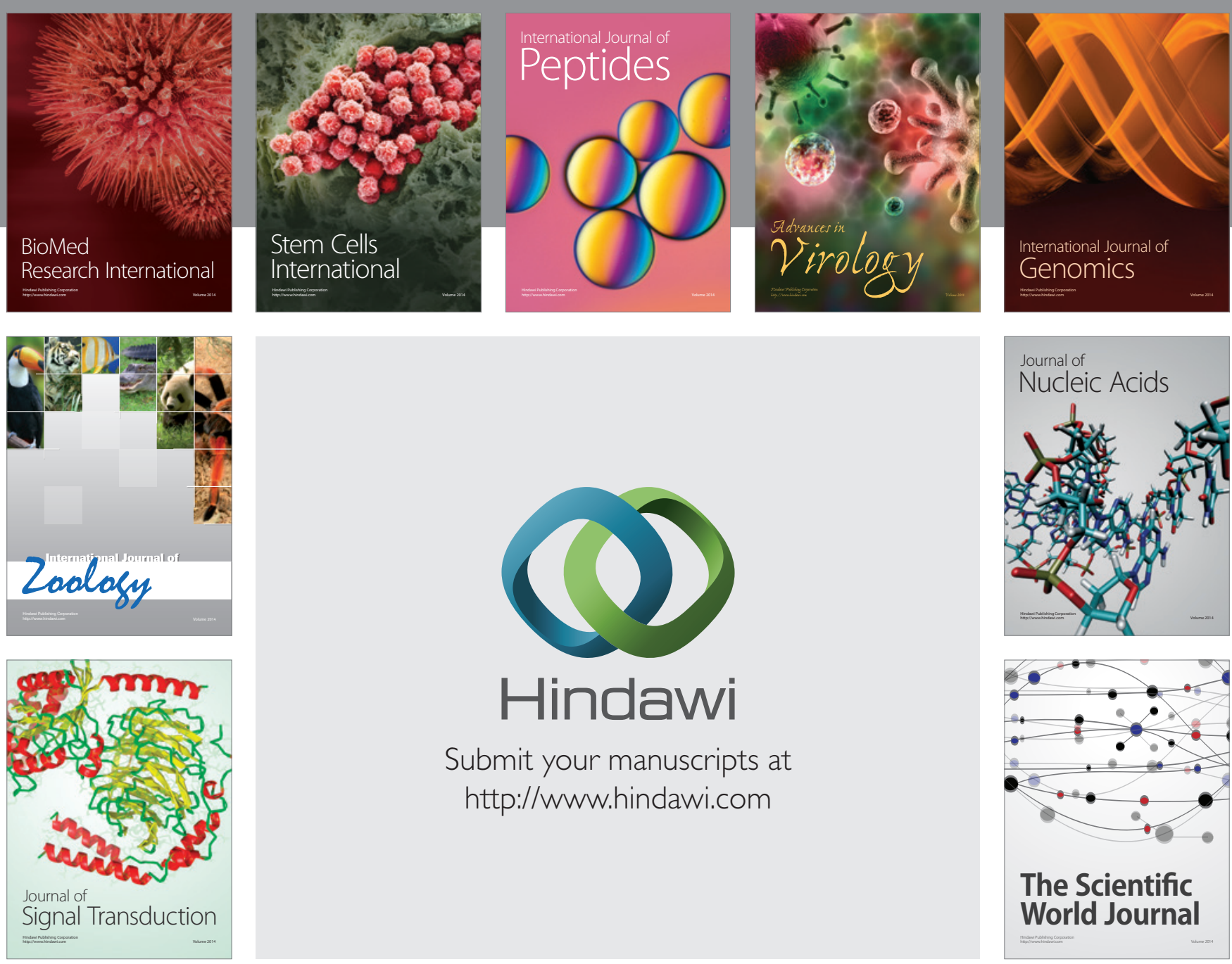

Submit your manuscripts at

http://www.hindawi.com
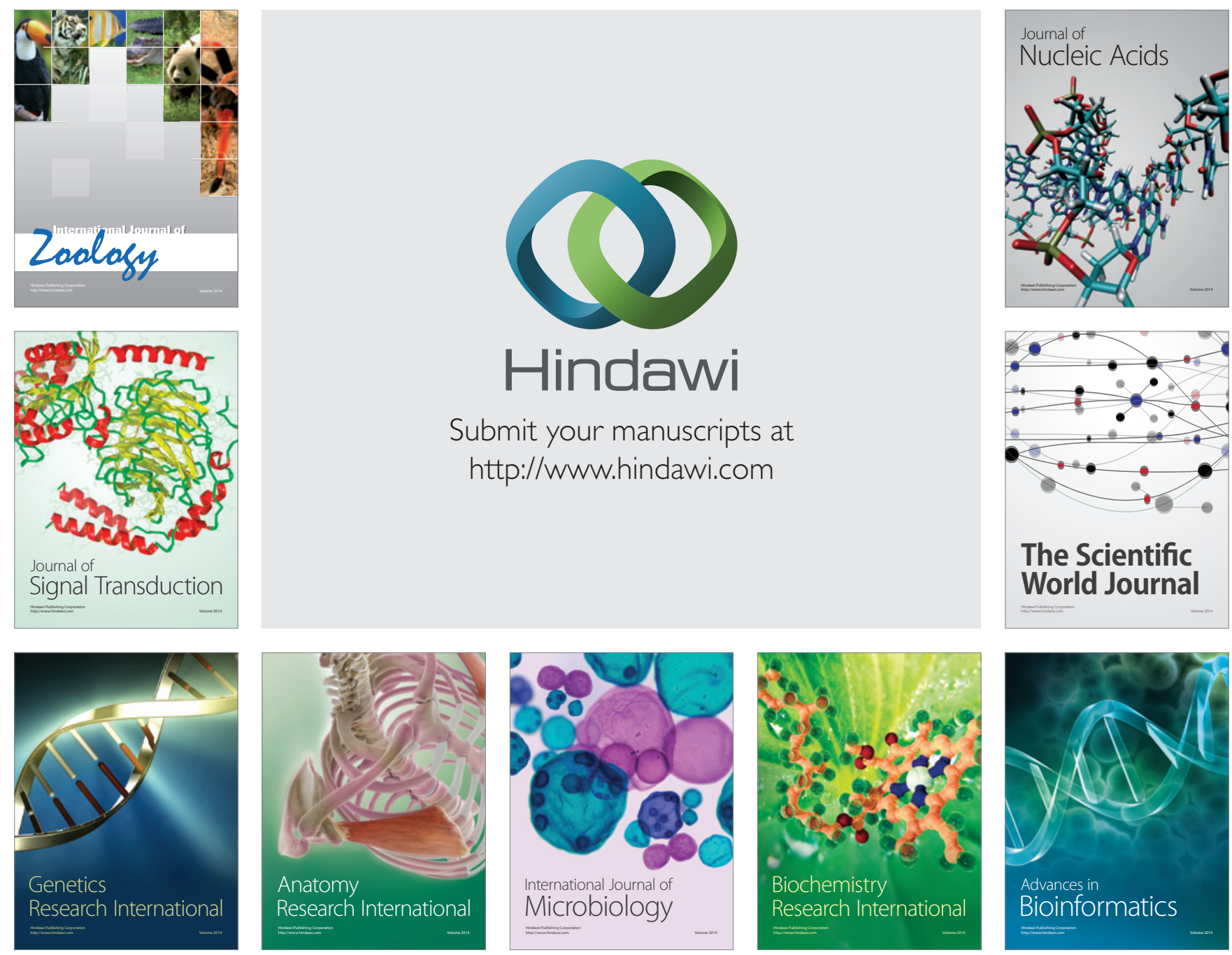

The Scientific World Journal
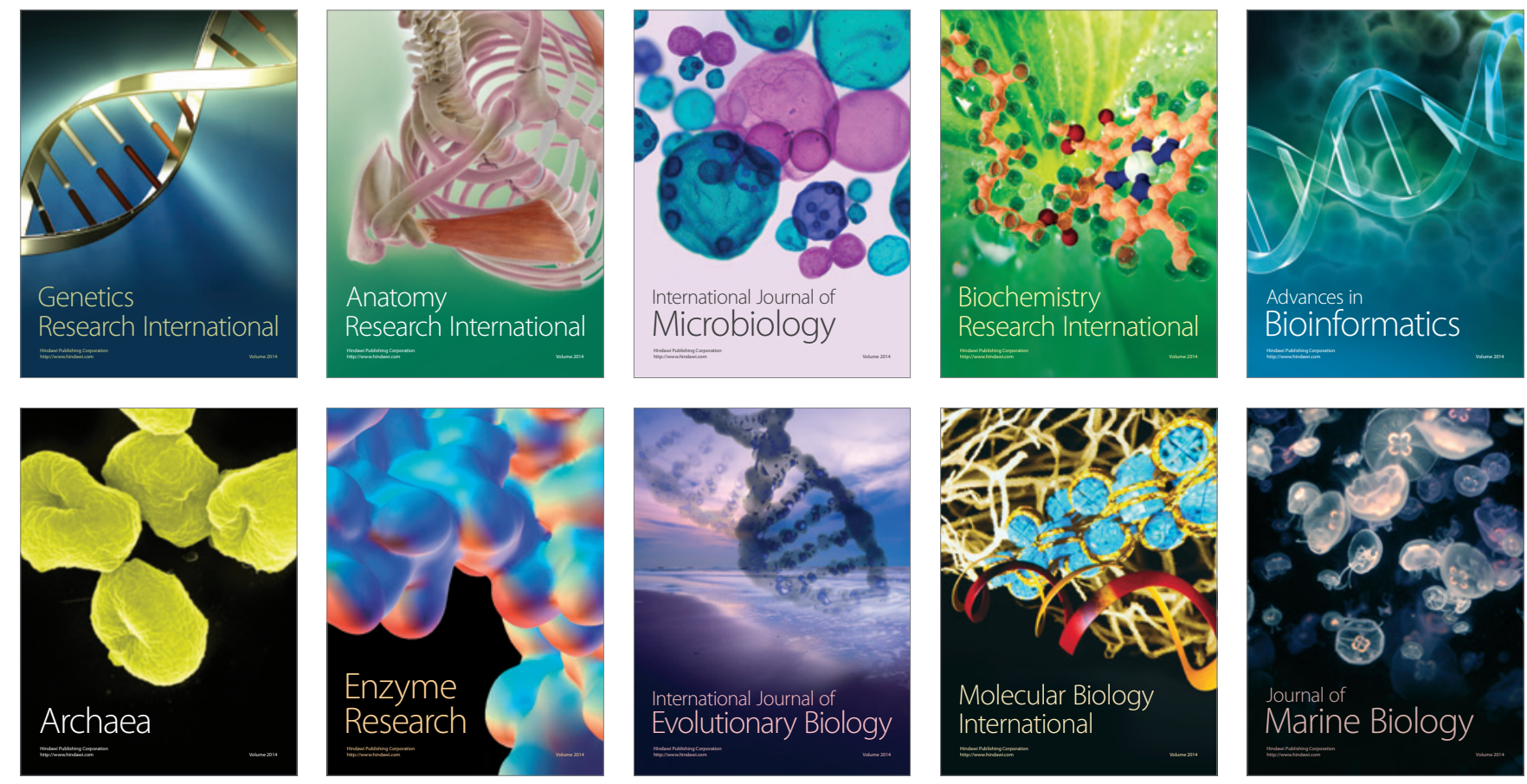